This is an electronic reprint of the original article. This reprint may differ from the original in pagination and typographic detail.

\author{
Author(s): Chivers, Tristram; Eisler, Dana; Fedorchuk, Chantall; Schatte, Gabriele; Tuononen, \\ Heikki; Boeré, René
}

Title: $\quad$ Stable spirocyclic neutral radicals: aluminum and gallium boraamidinates

Year: $\quad 2005$

Version:

Please cite the original version:

Chivers, T., Eisler, D., Fedorchuk, C., Schatte, G., Tuononen, H., \& Boeré, R. (2005). Stable spirocyclic neutral radicals: aluminum and gallium boraamidinates. Chemical Communications, (31), 3930-3932. https://doi.org/10.1039/B506253E

All material supplied via JYX is protected by copyright and other intellectual property rights, and duplication or sale of all or part of any of the repository collections is not permitted, except that material may be duplicated by you for your research use or educational purposes in electronic or print form. You must obtain permission for any other use. Electronic or print copies may not be offered, whether for sale or otherwise to anyone who is not an authorised user. 


\title{
Stable Spirocyclic Neutral Radicals: Aluminum and Gallium Boraamidinates
}

\author{
Tristram Chivers, ${ }^{* a}$ Dana J. Eisler, Chantall Fedorchuk, Gabriele Schatte, Heikki M. Tuononen and \\ René T. Boeré ${ }^{b}$
}

Stable dark red $(\mathrm{M}=\mathrm{Al})$ or dark green $(\mathrm{M}=\mathrm{Ga})$ neutral radicals $\left\{\left[\mathrm{PhB}\left(\mu-\mathrm{N}^{t} \mathrm{Bu}\right)_{2}\right]_{2} \mathrm{M}\right\}^{\bullet}$ are obtained by the oxidation of their corresponding anions with iodine, and EPR spectra supported by DFT calculations show that the spin density is equally delocalized over all four nitrogen atoms in these spiroconjugated systems.

The study of radicals of the heavier main-group elements is a fascinating undertaking that, through a combination of X-ray structural studies, EPR spectroscopy and theoretical calculations, provides informative insights into the bonding arrangements in odd-electron systems. ${ }^{1}$ In Group 13 chemistry, many of the socalled stable radicals ${ }^{2}$ are obtained as charged species, that is, in salts as either anion or cation radicals. The neutral paramagnetic complexes of the type $\left[\mathrm{M}(\mathrm{dbdab})_{2}\right]^{\bullet}(\mathrm{M}=\mathrm{Al}, \mathrm{Ga}$; dbdab $=1,4$-ditert-butyl-1,4-diazabutadiene) have been formulated as $\left(\mathrm{dbdab}^{-}\right) \mathrm{M}\left(\mathrm{dbdab}^{2-}\right) \mathrm{M}(\mathrm{III})$ complexes, in which the spin is located on one of the dbdab ligands, on the basis of EPR ${ }^{3 a}$ and UV-PES<smiles>[R]P=NP</smiles>

A

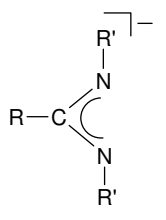

B

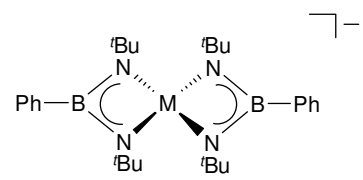

1a, $\mathrm{M}=\mathrm{Al}$

$1 \mathrm{~b}, M=\mathrm{Ga}$
$1 \mathrm{c}, \mathrm{M}=\mathrm{In}$ spectra. $^{3 \mathrm{~b}}$

The boraamidinate ligand $\left[\mathrm{RB}\left(\mathrm{NR}^{\prime}\right)_{2}\right]^{2-}(\mathbf{A})^{4}$ is isoelectronic with the extensively studied amidinate anions $\left[\mathrm{RC}\left(\mathrm{NR}^{\prime}\right)_{2}\right]^{-}(\mathbf{B}) .^{5}$ Early work on ligands of the type $\mathbf{A}$ was limited primarily to complexes of Group 4 or Group 14 metals. ${ }^{4}$ Interest in these dianionic ligands has been rekindled recently through reports of (a) complexes in which the ligand $\mathbf{A}$ bridges very short $\mathrm{M} \equiv \mathrm{M}$ triple bonds $(\mathrm{M}=\mathrm{Mo}$, W) ${ }^{6 a}$ (b) trisubstituted octahedral Group 4 dianions, ${ }^{6 \mathrm{~b}}$ and (c) the spirocyclic Group 13 anions $\left\{\left[\mathrm{PhB}\left(\mu-\mathrm{N}^{t} \mathrm{Bu}\right)_{2}\right]_{2} \mathrm{M}\right\}^{-}(\mathbf{1 b}, \mathbf{M}=\mathrm{Ga}$; 1c, $\mathrm{M}=\mathrm{In}) .^{7}$ The first structural characterizations of lithium derivatives of $\mathbf{A}$, which form dimeric or trimeric clusters, have also been described. ${ }^{8}$ An intriguing feature of the latter reagents is the formation of coloured solutions upon oxidation, which are thought to contain anion radicals of the type $\left[\mathrm{RB}\left(\mathrm{NR}^{\prime}\right)_{2}\right]^{\bullet} \cdot{ }^{9}$ We report here the first examples of the stabilization of these paramagnetic chelating ligands, which is achieved via coordination to Group 13 metal centres in the neutral spirocyclic radicals $\{[\operatorname{PhB}(\mu$ $\left.\left.\left.\mathrm{N}^{t} \mathrm{Bu}\right)_{2}\right]_{2} \mathrm{M}\right\}^{\bullet}(\mathbf{2 a}, \mathrm{M}=\mathrm{Al} ; \mathbf{2 b}, \mathrm{M}=\mathrm{Ga})$.
Treatment of one equivalent of the dilithiated boraamidinate $\mathrm{Li}_{2}\left[\mathrm{PhB}\left(\mu-\mathrm{N}^{t} \mathrm{Bu}\right)_{2}\right] \quad$ with one equivalent of $\{[\mathrm{PhB}(\mu-$ $\left.\left.\left.\mathrm{N}^{t} \mathrm{Bu}\right)_{2}\right] \mathrm{AlCl}\left(\mathrm{OEt}_{2}\right)\right\}(3)^{10}$ in a boiling mixture of benzene and diethyl ether produces the aluminum boraamidinate complex $\{\mu$ $\left.\mathrm{Li}\left(\mathrm{OEt}_{2}\right)\left[\mathrm{PhB}\left(\mu-\mathrm{N}^{t} \mathrm{Bu}\right)_{2}\right]_{2} \mathrm{Al}\right\} \quad(4 \mathbf{a}) . \dagger$ Subsequent reaction of either 4a or $\left\{\mu-\mathrm{Li}\left(\mathrm{OEt}_{2}\right)\left[\mathrm{PhB}\left(\mu-\mathrm{N}^{t} \mathrm{Bu}\right)_{2}\right]_{2} \mathrm{Ga}\right\}^{7} \quad$ (4b) with iodine immediately generates dark red or dark green solutions, respectively (Scheme 1). $\dagger$ Dark red crystals of $\mathbf{2 a}$ and dark green crystals of $\mathbf{2 b}$ suitable for X-ray structural determinationsł were grown from concentrated diethyl ether solutions at $258 \mathrm{~K}$. These radicals are stable in the solid state under an inert atmosphere at room temperature for weeks.

$\mathrm{X}$-ray structural determinations revealed that complexes $\mathbf{2 a}$ and

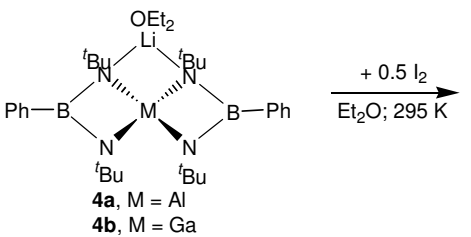

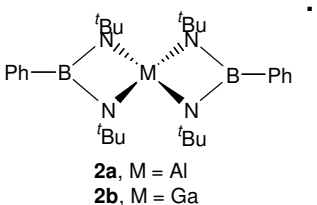

Scheme 1 Oxidation of $4 \mathbf{a}$ and $\mathbf{4 b}$ with iodine.

2b are isostructural. The molecular structures and pertinent structural parameters for $\mathbf{2 a}$ and $\mathbf{2 b}$ are depicted in Figure 1. In each case, the molecule lies on a crystallographic two-fold axis which imposes crystallographic equivalence on the two

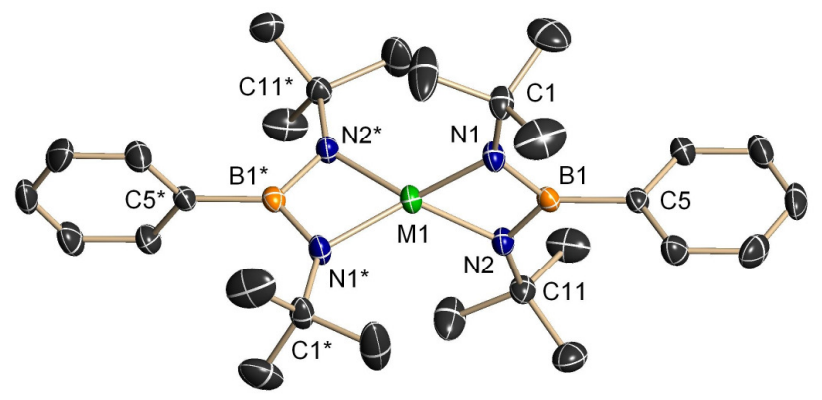

Fig. 1 X-ray crystal structure of $\mathbf{2 a}(M=A l)$ and $\mathbf{2} \mathbf{b}(M=G a)(H$-atoms are omitted): Selected bond lengths $[\AA]$ and bond angles $\left[{ }^{\circ}\right]$ [PBE0/TZVP optimized parameters are in square brackets]. 2a: $\mathrm{Al}(1)-\mathrm{N}(1) 1.842(2)$ [1.859], $\mathrm{Al}(1)-\mathrm{N}(2)$ 1.852(2), N(1)-B(1) $1.445(3)$ [1.442], N(2)-B(1) 1.449(3), N(1)-Al(1)-N(1)* 128.5(1) [128.2], N(1)-Al(1)-N(2) 76.37(9) [76.3], N(1)*-Al(1)-N(2) 127.99(9), $\mathrm{N}(2)-\mathrm{Al}(1)-\mathrm{N}(2) * 128.2(1), \mathrm{N}(1)-\mathrm{B}(1)-\mathrm{N}(2)$ 104.2(2) [105.6]; 2b: $\mathrm{Ga}(1)-\mathrm{N}(1)$ 1.923(2) [1.928], Ga(1)-N(2) 1.922(2), N(1)-B(1) $1.445(3)$ [1.437], N(2)-B(1) 1.438(3), N(1)-Ga(1)-N(1)* 130.9(1) [130.4], N(1)-Ga(1)-N(2) 72.81(9) [72.8], N(1)*-Ga(1)-N(2) 130.02(9), $\mathrm{N}(2)-\mathrm{Ga}(1)-\mathrm{N}(2) * 130.6(1), \mathrm{N}(1)-\mathrm{B}(1)-\mathrm{N}(2)$ 104.7(2) [105.5]. Symmetry transformations used to generate equivalent atoms: ${ }^{*}-\mathrm{x}, \mathrm{y},-\mathrm{z}$ $+1 / 2$. 
boraamidinate ligands. The two planes defining these ligands are mutually orthogonal [2a: $\left.\angle 89.7(2)^{\circ} ; \mathbf{2 b}: \angle 89.2(2)^{\circ}\right]$. The fourmembered $\mathrm{BN}_{2} \mathrm{M}$ rings in $\mathbf{2 a}$ and $\mathbf{2 b}$ are essentially planar. The metrical parameters of the boraamidinate ligands in $\mathbf{2 a}$ and $\mathbf{2} \mathbf{b}$ are identical within experimental error. For example, the boron and nitrogen atoms all exhibit distorted trigonal planar geometries; the sum of the bond angles is close to $360^{\circ}$ in each case [2a: $\mathrm{B}(1)$, $359.9(2)^{\circ} ; \mathrm{N}(1), 359.9(2)^{\circ} ; \mathrm{N}(2), 360.0(2)^{\circ} .2 \mathbf{b}: \mathrm{B}(1), 360.1(2)^{\circ}$; $\left.\mathrm{N}(1), 360.0(2)^{\circ} ; \mathrm{N}(2), 359.8(2)^{\circ}\right]$. The geometry about the central metal atom is distorted tetrahedral (bond angle range 76.37(9)-128.5(1) ${ }^{\circ}, \mathbf{2 a} ; 72.81(9)-130.9(1)^{\circ}$, 2b). In each of the structures, the two $\mathrm{M}-\mathrm{N}$ and all $\mathrm{B}-\mathrm{N}$ bond distances are equal within the limit of experimental error. As expected from relative sizes of $\mathrm{M}^{3+}$ ions, ${ }^{11}$ the $\mathrm{Al}-\mathrm{N}$ distances in $\mathbf{2 a}$ are ca. $0.08 \AA$ shorter than the corresponding $\mathrm{Ga}-\mathrm{N}$ distances in $\mathbf{2} \mathbf{b}$.

Theoretical calculations $\dagger$ were first carried out on the $\mathrm{D}_{2 \mathrm{~d}}$ symmetric diamagnetic model systems $\left\{\left[\mathrm{PhB}(\mu-\mathrm{NMe})_{2}\right]_{2} \mathrm{M}\right\}^{-}(\mathrm{M}$ $=\mathrm{Al}, \mathrm{Ga}$ ) to evaluate their frontier orbitals. For both $\mathrm{M}=\mathrm{Al}$ and $\mathrm{Ga}$, the HOMO transforms as the a2 irreducible representation in the $\mathrm{D}_{2 \mathrm{~d}}$ point group (Figure $\mathrm{S} 1$ ). Thus, a one-electron oxidation will yield the corresponding neutral radicals $\{[\operatorname{PhB}(\mu$ $\left.\left.\mathrm{NMe})_{2}\right]_{2} \mathrm{M}\right\}^{\bullet}$ with ${ }^{2} \mathrm{~A}_{2}$ ground state and $\mathrm{D}_{2 \mathrm{~d}}$ symmetry.

Similar to the model systems, the spirocyclic radicals $2 \mathbf{a}$ and 2b are also expected to retain the $\mathrm{D}_{2 \mathrm{~d}}$ symmetry of their parent diamagnetic anions $\left\{\left[\mathrm{PhB}\left(\mu-\mathrm{N}^{t} \mathrm{Bu}\right)_{2}\right]_{2} \mathrm{M}\right\}^{-}(\mathrm{M}=\mathrm{Al}, \mathrm{Ga})$. This is confirmed by X-ray structural analyses of $\mathbf{2} \mathbf{a}$ and $\mathbf{2} \mathbf{b}$ (vide supra) that reveal only slight deviations from idealized structures (Figure 1). The retention of the $D_{2 d}$ symmetry in $\mathbf{2 a}$ and $\mathbf{2} \mathbf{b}$ is in sharp contrast to the observations for the related diazabutadiene radicals

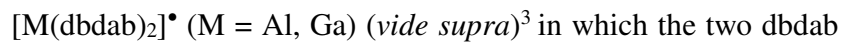
ligands exhibit distinctly different metrical parameters. This was explained recently by using DFT calculations, ${ }^{12}$ which revealed that the HOMOs of the $\mathrm{D}_{2 \mathrm{~d}}$ symmetric diamagnetic anions $\left[\mathrm{M}(\mathrm{dbdab})_{2}\right]^{-}(\mathrm{M}=\mathrm{Al}, \mathrm{Ga})$ are doubly degenerate orbitals of esymmetry. Upon oxidation, an unstable partially filled degenerate set of orbitals is formed that incurs a Jahn-Teller distortion. Hence, the resulting radicals adopt $\mathrm{C}_{2 \mathrm{v}}$ symmetry with mixedvalent dbdab ligands and localized spin density. ${ }^{12}$ In comparison, the diamagnetic anions in $\mathbf{4}$ are also $\mathrm{D}_{2 \mathrm{~d}}$ symmetric, however, the HOMO of these systems is not comprised of a degenerate set of orbitals. Thus, neither Jahn-Teller distortion nor spin localization are of consequence upon oxidation.

a)

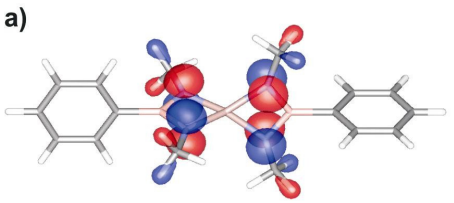

b)

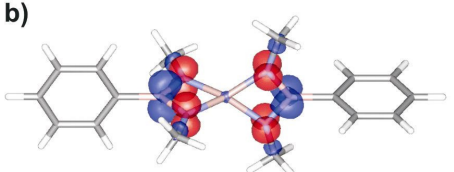

Fig. 2 a) The SOMO of $\left\{\left[\mathrm{PhB}(\mu \text {-NMe })_{2}\right]_{2} \mathrm{Al}\right\}^{\bullet}$ drawn at isosurface level \pm 0.05 . b) Spin density map of $\left\{\left[\mathrm{PhB}(\mu-\mathrm{NMe})_{2}\right]_{2} \mathrm{Al}\right\}^{\circ}$ drawn at isosurface levels 0.02 ( $\alpha$-spin density, red) and -0.002 ( $\beta$-spin density, blue).
Single point calculations for the model radicals $\{[\mathrm{PhB}(\mu-$ $\left.\left.\mathrm{NMe})_{2}\right]_{2} \mathrm{M}\right\}^{\bullet}(\mathrm{M}=\mathrm{Al}, \mathrm{Ga})$ in their optimized geometries show that their SOMOs consist solely of nitrogen $p$-orbitals and are equally delocalized over all four nitrogen atoms (Figure 2a). Thus the conditions for spiroconjugation are fulfilled. ${ }^{13}$ Similarly, Mulliken population analysis reveals the spin density to be equally distributed among all nitrogen centres. Although the

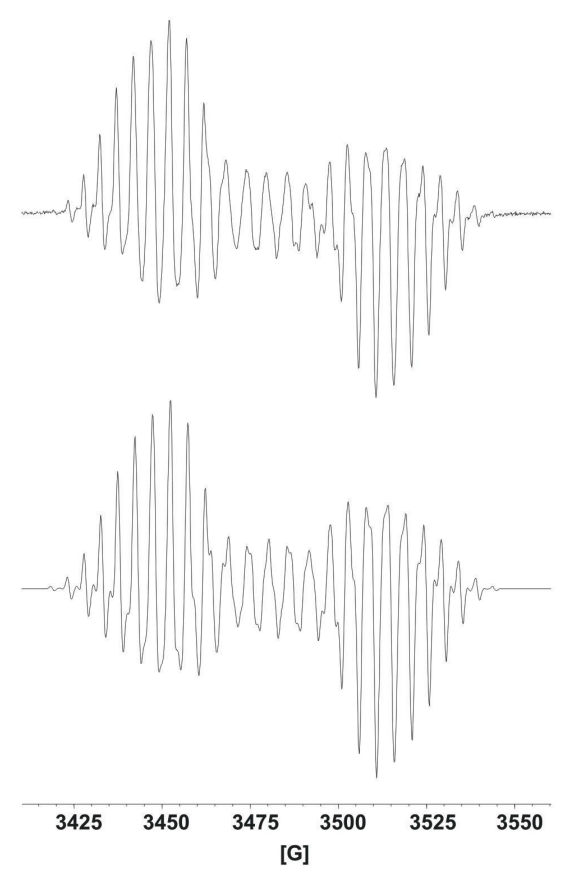

Fig. 3 Experimental (a) and simulated (b) X-band EPR spectra of a diethyl ether solution of $\mathbf{2 a}$ at $295 \mathrm{~K}$.
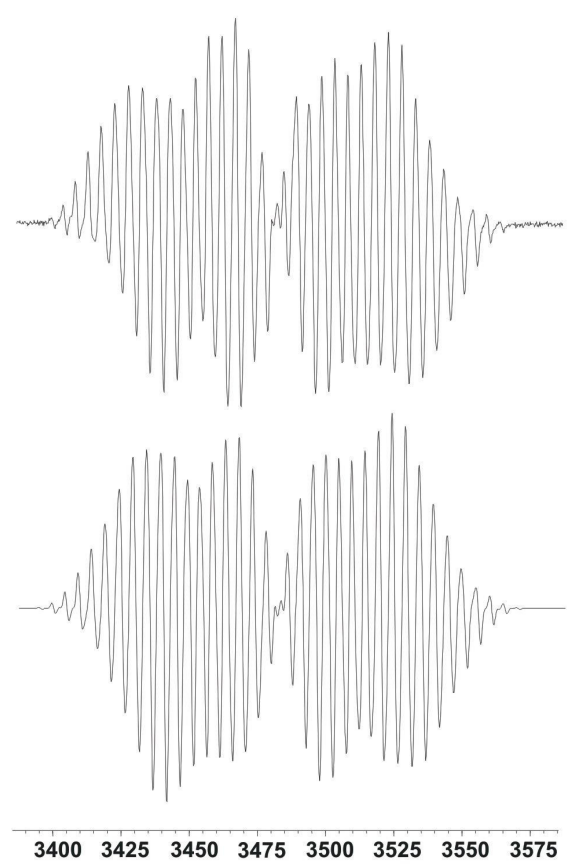

[G]

Fig. 4 Experimental (a) and simulated (b) X-band EPR spectra of a diethyl ether solution of $\mathbf{2 b}$ at $295 \mathrm{~K}$. 
SOMOs do not include contributions from boron or from the central metal, these atoms also have non-zero spin density values arising from the spin polarization effects (Figure 2b). In consequence, the EPR spectra of both spirocyclic radicals are expected to show hyperfine structure due to the central metal (2a: ${ }^{27} \mathrm{Al}, I=5 / 2,100 \% ; \mathbf{2 b}:{ }^{69} \mathrm{Ga}, I=3 / 2,60.4 \% ;{ }^{71} \mathrm{Ga}, I=3 / 2$, $39.6 \%)$, two equivalent boron atoms $\left({ }^{10} \mathrm{~B}, I=3,19.6 \% ;{ }^{11} \mathrm{~B}, I=\right.$ $3 / 2,80.4 \%)$ and four equivalent nitrogen $\left({ }^{14} \mathrm{~N}, I=1,99.6 \%\right)$ centres.

Table 1 Experimental ${ }^{a}$ and Calculated Hyperfine Coupling Constants [G]

\begin{tabular}{lllll}
\hline $\begin{array}{l}\{[\mathrm{PhB}(\boldsymbol{\mu}- \\
\left.\left.\mathrm{NR})_{2}\right]_{2} \mathrm{M}\right\}^{\bullet}\end{array}$ & isotope & $\mathbf{n}^{b}$ & $\begin{array}{l}\text { exptl. } \\
\left(\mathrm{R}={ }^{t} \mathrm{Bu}\right)\end{array}$ & $\begin{array}{l}\text { calc. }^{c} \\
(\mathrm{R}=\mathrm{Me})\end{array}$ \\
\hline $\mathrm{M}=\mathrm{Al}^{d}$ & ${ }^{27} \mathrm{Al}$ & 1 & 11.47 & -16.86 \\
& ${ }^{14} \mathrm{~N}$ & 4 & 4.66 & 4.17 \\
& ${ }^{10} \mathrm{~B}$ & & 1.72 & -2.01 \\
& ${ }^{11} \mathrm{~B}$ & 2 & 5.15 & -6.03 \\
& & & & \\
$\mathrm{M}=\mathrm{Ga}^{e}$ & ${ }^{69} \mathrm{Ga}$ & & 28.00 & -45.61 \\
& ${ }^{71} \mathrm{Ga}$ & 1 & 35.40 & -57.67 \\
& ${ }^{14} \mathrm{~N}$ & 4 & 4.69 & 4.27 \\
& ${ }^{10} \mathrm{~B}$ & 2 & 1.73 & -2.03 \\
& ${ }^{11} \mathrm{~B}$ & 2 & 5.20 & -6.10 \\
\hline
\end{tabular}

\footnotetext{
${ }^{a}$ Parameters were determined from simulations optimized to match the experimental spectra; very close agreement between experiment and simulation was obtained (Figures 3 and 4 ). ${ }^{b}$ Number of nuclei. ${ }^{c}$ Details of computational methods used are given in the supplementary information. ${ }^{d} 100 \%$ Lorentzian line shapes with a LW of $1.05 \mathrm{G} .{ }^{e} 100 \%$ Lorentzian line shapes with a LW of $1.30 \mathrm{G}$.
}

Figures $3 \mathrm{a}$ and $4 \mathrm{a}$ show the experimental EPR spectra of 2a and $\mathbf{2 b}$, respectively. Both radicals give intensely coloured solutions (vide supra) in diethyl ether or benzene that persist for days $(\mathrm{M}=\mathrm{Al})$ or several hours $(\mathrm{M}=\mathrm{Ga})$ at room temperature. Excellent simulations of the spectra were obtained by using the hyperfine coupling (hfc) constants given in Table 1. In general, there is a very good agreement between the experimental and the calculated hfc values (Table 1). ${ }^{14}$ Hence, the spectral simulations and DFT calculations indicate uniform spin delocalization throughout both boraamidinate ligands in $\mathbf{2 a}$ and $\mathbf{2 b}$ and confirm the retention of spirocyclic structures in solution.

In summary, the neutral radicals $\mathbf{2 a}$ and $\mathbf{2 b}$ are the first examples of complexes in which a boraamidinate anion radical $\left[\mathrm{PhB}\left(\mathrm{N}^{t} \mathrm{Bu}\right)_{2}\right]^{-\bullet}$ is stabilized by coordination to a metal centre. They also provide an unique example of spiroconjugation in a purely inorganic framework. ${ }^{16}$ The isolation of these paramagnetic complexes suggests that redox behaviour may be a more important feature of boraamidinate complexes than heretofore recognized.

Tristram Chivers, ${ }^{* a}$ Dana J. Eisler, Chantall Fedorchuk, Gabriele Schatte, Heikki M. Tuononen and René T. Boeré ${ }^{b}$

${ }^{a}$ Department of Chemistry, University of Calgary, Calgary, Alberta, Canada T2N 1N4. Fax: +1 (403) 289-9488; Tel: + 1 (403) 220-5741; Email: chivers@ucalgary.ca

${ }^{b}$ Department of Chemistry and Biochemistry, University of Lethbridge, Lethbridge, Alberta, Canada T1K 3M4. Fax: +1 (403) 329-2057; Tel: +1 (403)329-2045; E-mail: boere@uleth.ca

\section{Notes and references}

Crystal data for 2a: $\mathrm{C}_{28} \mathrm{H}_{46} \mathrm{AlB}_{2} \mathrm{~N}_{4}, M_{\mathrm{r}}=487.29$, orthorhombic, Pbcn, $a=17.252(4), b=8.911(2), c=20.212(4) \AA, V=3107.1(1) \AA^{3}, Z=$ $4, T=173(2) \mathrm{K}, \mu(\mathrm{Mo}-\mathrm{K} \alpha)=0.086 \mathrm{~mm}^{-1}, 15287$ reflections collected, 2712 unique $\left(R_{\text {int }}=0.068\right), R_{1}=0.0577[I>2 \sigma(I)], w R_{2}=$ 0.1468 (all data). 2b: $\mathrm{C}_{28} \mathrm{H}_{46} \mathrm{GaB}_{2} \mathrm{~N}_{4}, M_{\mathrm{r}}=530.03$, orthorhombic, Pbcn, $a=17.173(3), b=8.945(2), c=20.337(4) \AA, V=3123.8(11)$ $\AA^{3}, Z=4, T=173(2) \mathrm{K}, \mu(\mathrm{Mo}-\mathrm{K} \alpha)=0.902 \mathrm{~mm}^{-1}, 49170$ reflections collected, 2756 unique $\left(R_{\text {int }}=0.056\right), R_{1}=0.0395[I>2 \sigma(I)], w R_{2}=$ 0.0926 (all data). CCDC-267896 and 267897. See http://www.rsc.org/suppdata/cc/??/???????? for crystallographic data in CIF or other electronic format.

1 For a recent review, see: P. P. Power, Chem. Rev., 2003, 103, 789-809.

2 As defined in ref. [1], the term "stable", as applied to radicals, is taken to indicate "a species that can be isolated and shows no sign of decomposition under an inert atmosphere at room temperature", whereas a "persistent" radical has "a relatively long lifetime under the conditions it is generated".

3 a) W. Kaim and W. Matheis, Chem. Commun., 1991, 597-598, and references therein; b) F. G. N. Cloke, C. I. Dalby, P. J. Daff and J. C. Green, J. Chem. Soc., Dalton Trans. 1991, 181-184.

4 For a short review, see: P. Blais, J. K. Brask, T. Chivers, C. Fedorchuk and G. Schatte, ACS Symposium Series, (Ed. P. J. Shapiro and D. A. Atwood), 2002, 822, 195-207.

5 For reviews, see: a) F. T. Edelmann, Coord. Chem. Rev., 1994, 137, 403-481; b) J. Barker and M. Kilner, Coord. Chem. Rev. 1994, 133, 219-300.

6 a) D. R. Manke, Z-H. Loh and D. G. Nocera, Inorg. Chem. 2004, 43 3618-3624; b) D. R. Manke and D. G. Nocera, Inorg. Chem. 2003, 42, 4431-4436.

7 T. Chivers, C. Fedorchuk, G. Schatte and M. Parvez, Inorg. Chem. 2003, 42, 2084-2093.

8 J. K. Brask, T. Chivers and G. Schatte, Chem. Commun. 2000, 1805-1806.

9 T. Chivers, C. Fedorchuk, G. Schatte and J. K. Brask, Can. J. Chem. $2002,80,821-831$

10 The monocyclic structure of $\mathbf{3}$ was confirmed by X-ray crystallography. Details will be given in a full account of this work.

11 R.D. Shannon, Acta Crystallogr. 1976, A32, 751-767.

12 W. W. Schoeller and S. Grigoleit, J. Chem. Soc., Dalton Trans. 2002, 405-409.

13 H. E. Simmons and T. Fukunaga, J. Am. Chem. Soc., 1967, 89, $5208-5215$.

14 The largest deviations occur for the metal centres and arise from two primary sources. First, the hfc values of metal centres arise purely from spin polarization effects, which are known to be extremely difficult to model accurately ${ }^{15}$ Second, the basis set used for gallium is energy-, not property-, optimized and does not include any enhanced s-part, a requirement for obtaining more than semiquantitative accuracy. ${ }^{15}$

15 M. L. Munzarová in Calculation of NMR and EPR parameters: Theory and Applications (Eds.: M. Kaupp, M. Bühl, V G. Malkin), $\mathrm{VCH}$, Weinheim, 2004, pp. 463-482.

16 A spirophenalenyl-based radical with a central tetrahedral $\mathrm{BO}_{2} \mathrm{~N}_{2}$ unit has been reported, but the spin density is highly delocalized onto the phenalene rings. X. Chi, M. E. Itkis, B. O. Patrick, T. M. Barclay, R. W. Reed, R. T. Oakley, A. W. Cordes and R. C. Haddon, J. Am. Chem. Soc., 1999, 121, 10395-10402. 